\title{
Female-specific regulation of skeletal muscle mass by USP19 in young mice
}

\section{Masahiro Ogawa, Tomoya Kitakaze, Naoki Harada and Ryoichi Yamaji}

Division of Applied Life Sciences, Graduate School of Life and Environmental Sciences, Osaka Prefecture University, Osaka 5998531, Japan
Correspondence should be addressed to R Yamaji

Email yamaji@biochem. osakafu-u.ac.jp

\begin{abstract}
$17 \beta$-estradiol $\left(E_{2}\right)$ is thought to be responsible for sex-specific differences in skeletal muscle mass. The biological function of $E_{2}$ is exerted through its binding to estrogen receptor $\alpha$ $(E R \alpha)$. The expression of ubiquitin-specific peptidase 19 (USP19) is upregulated during muscle atrophy and by $E_{2}$-activated ER $\alpha$. Here, we investigated the involvement of USP19 in sex difference in muscle mass in young mice. Knockdown of USP19 in hindlimb muscles increased the mass and fiber size in soleus muscle in females but not males. Using Usp19 promoter reporter constructs, a functional half-estrogen response element (hERE) was identified in intron 1 of Usp19. ER $\alpha$ bound to hERE in an $\mathrm{E}_{2}$-dependent manner in $\mathrm{C} 2 \mathrm{C} 12$ myoblasts and in soleus muscle in ovariectomized (OVX) female mice. Furthermore, under normal physiological conditions, ER $\alpha$ bound to hERE in soleus muscle only in females. In contrast, administration of $E_{2}$ resulted in increased Usp19 mRNA expression, decreased muscle mass, and recruitment of ER $\alpha$ to hERE in soleus muscle in males. Knockdown of ER $\alpha$ in hindlimb muscles decreased Usp19 mRNA expression and increased the mass of soleus muscle only in females. Knockdown of USP19 resulted in increased levels of ubiquitin conjugates in soleus muscle in females. OVX increased the levels of ubiquitin conjugates and administration of $E_{2}$ decreased OVX-induced levels of ubiquitin conjugates. These results demonstrate that in soleus muscle in young female mice under physiological conditions, $E_{2}$ upregulates USP19 expression through ER $\alpha$ and consequently leads to decreases in ubiquitin conjugates and muscle mass.
\end{abstract}

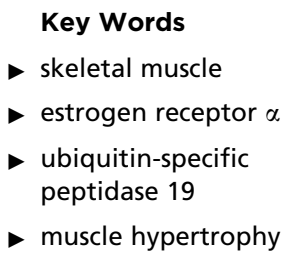

Journal of Endocrinology (2015) 225, 135-145

\section{Introduction}

Body composition and body size are different between males and females. Sex hormones such as androgens and estrogens are thought to be responsible for sex-specific differences not only in reproductive tissues, but also in peripheral tissues such as skeletal muscle, adipose, and bone (Heldring et al. 2007). Administration of the estrogen $17 \beta$-estradiol $\left(\mathrm{E}_{2}\right)$ reduces soleus muscle fiber size in young ovariectomized (OVX) female rats (McCormick et al. 2004) and decreases soleus muscle mass in young female mice (Ihemelandu 1981). We previously reported that $\mathrm{E}_{2}$ replacement decreases the muscle mass in young OVX mice (Ogawa et al. 2011). However, the mechanism by which $\mathrm{E}_{2}$ decreases skeletal muscle mass in young females is unclear. Therefore, it is important to identify and characterize target molecules that regulate skeletal muscle mass in a sex-specific fashion in young female mice.

Published by Bioscientifica Ltd 
Skeletal muscle is the largest tissue in all mammals and accounts for $30-40 \%$ of the whole body weight in humans. Because this tissue plays important roles in not only mobility, but also metabolism of glucose and triglyceride, the loss of muscle mass results in decreased mobility, ultimately immobility and metabolic diseases such as obesity and type 2 diabetes (Bergeron et al. 1999, Kiens 2006, Srikanthan et al. 2010). During embryogenesis, the myoblasts fuse into multinucleated myotubes that eventually form myofibers (called myogenesis) (Abmayr \& Pavlath 2012). Postnatal growth of skeletal muscle is achieved by either extensive fusion of myoblasts with the growing myofibers (hyperplasia) or an increase in the size of individual myofibers (hypertrophy) (White et al. 2010). In mice, hyperplasia stops around 3 weeks after birth (Gokhin et al. 2008), and then hypertrophy mainly contributes to an increase in skeletal muscle mass (Ontell et al. 1984). Hypertrophy occurs due to increased net protein within an individual myofiber with no addition of myonuclei.

Skeletal muscle mass is regulated by the balance between synthesis and degradation of muscle proteins, and the loss of muscle mass results from increased protein degradation (Evans 2010). The ubiquitin-proteasome system serves to degrade aberrant proteins. The conjugation of ubiquitin to muscle proteins is accomplished by a cascade of enzymes, ubiquitin-activating enzymes, ubiquitin-conjugating enzymes, and ubiquitin ligases, and subsequently the conjugated proteins are degraded by the proteasome (Hershko \& Ciechanover 1992). In addition, deubiquitinating enzymes, which are called ubiquitinspecific peptidases (USPs), also regulate the ubiquitinproteasome system. The USPs release ubiquitin from nonspecific ubiquitin-conjugated proteins to maintain intracellular ubiquitin level or remove ubiquitin from specific ubiquitin-conjugated proteins to protect them from proteasomal degradation (Tiao et al. 1997). The expression levels of two deubiquitinating enzymes, USP14 and USP19, are increased in skeletal muscle during catabolic states (Combaret et al. 2005, Srikanthan et al. 2010, Liu et al. 2011, Ogawa et al. 2013). Overexpression of USP19 inhibits myogenesis, whereas depletion of USP19 promotes myogenesis (Ogawa et al. 2011) and inhibits dexamethasone-induced muscle atrophy in L6 cells (Sundaram et al. 2009).

The biological functions of $E_{2}$ are exerted through its binding to two estrogen receptors (ERs), ER $\alpha$ and ER $\beta$ (Heldring et al. 2007). The ERs bind to estrogen response elements (EREs) in the promoter regions of estrogenresponsive genes, followed by transcriptional activation of their genes (Heldring et al. 2007). The EREs are palindromic sequences and sometimes one half of the ERE (hERE) is effective. Because ER $\alpha$ and ER $\beta$ competitively bind to the same EREs or specifically bind to different EREs, they do not function redundantly in gene regulation. The two ER isoforms are expressed in the skeletal muscle (Wiik et al. 2009) and seem to play different biological roles in skeletal muscle development (Barros et al. 2006, Brown et al. 2009). We previously found that $\mathrm{E}_{2}$ represses myogenic differentiation, which occurs during developmental and postnatal myogenesis, by increasing Usp19 gene expression through $\mathrm{ER} \alpha$ and that $\mathrm{E}_{2}$ replacement increases USP19 expression level in soleus muscle in young OVX mice (Ogawa et al. 2011). These findings led us to study the roles of ER $\alpha$ and USP19 in skeletal muscle mass in young male and female mice under physiological conditions. The purpose of this study was to determine how ER $\alpha$ upregulates Usp19 gene expression and whether USP19 is involved in difference in skeletal muscle mass between males and females in young mice. Our data provide evidence that $\mathrm{ER} \alpha$ upregulates Usp19 gene expression in young female mice, but not in male mice, in an $\mathrm{E}_{2}$-dependent manner under physiological conditions and that consequently USP19 decreases soleus muscle mass in young females.

\section{Materials and methods}

\section{Animals}

The care of all animals in the present study was in accordance with the guidelines of the Animal Care and Use Committee of Osaka Prefecture University. Female Kwl:ddY mice and male Kwl:ddY mice were obtained from Kiwa Laboratory Animals (Wakayama, Japan) at 6 weeks of age and at 7 weeks of age, respectively. The mice had free access to water and food (phytoestrogen-free AIN76 diet (Lephart et al. 2004) in which sucrose was replaced with cornstarch). The mice were kept at controlled temperature $\left(23 \pm 2{ }^{\circ} \mathrm{C}\right)$, humidity $(60 \pm 10 \%)$ and lighting (a $12 \mathrm{~h}$ light: $12 \mathrm{~h}$ darkness cycle starting at $0800 \mathrm{~h}$ ).

\section{Ovariectomy and $E_{2}$ injection}

Female mice at 7 weeks of age were OVX and were randomly divided into two groups ( $n=5$ per group). After 1 week, one group was injected with estradiol valerate $(0.1 \mathrm{mg} / \mathrm{kg}$ body weight; Mochida Pharmaceutical, Tokyo, Japan) into the thigh muscles. The other group was intramuscularly injected with vehicle (sesame oil).

Published by Bioscientifica Ltd. 
Two groups ( $n=5$ per group) of male mice at 8 weeks of age were treated in the same way. One week after injection, the mice were sacrificed by exsanguination under anesthesia. The soleus muscles were isolated, weighed, frozen in liquid nitrogen, and stored at $-80{ }^{\circ} \mathrm{C}$ until use.

\section{Cell culture}

Mouse C2C12 skeletal muscle myoblasts were obtained from RIKEN Cell Bank (Tsukuba, Japan) and were maintained as previously described (Ogawa et al. 2011). Briefly, C2C12 myoblasts were grown to confluence in DMEM supplemented with $10 \% \mathrm{v} / \mathrm{v}$ fetal bovine serum, 100 units $/ \mathrm{ml}$ penicillin, and $100 \mu \mathrm{g} / \mathrm{ml}$ streptomycin (growth medium) at $37^{\circ} \mathrm{C}$ in $5 \% \mathrm{CO}_{2}$ and $95 \%$ air atmosphere at $100 \%$ humidity. To induce differentiation, C2C12 myoblasts were grown to $90 \%$ confluence in the growth medium and then cultured in DMEM supplemented with $2 \% \mathrm{v} / \mathrm{v}$ horse serum (differentiation medium) unless otherwise indicated. The differentiation medium was replaced at $48 \mathrm{~h}$ intervals.

\section{Construction of reporter vectors and promoter assay}

The nucleotide sequence $(-152$ to +1902$)$ including a putative hERE $(+301$ to +306$)$ in murine Usp19 gene was amplified by PCR using genomic DNA from C2C12 myoblasts. The amplified DNA was subcloned into pGL4.20 plasmid (Promega), termed pUSP19-hERE. A portion of the putative hERE was mutated by site-directed mutagenesis from 5'-AGGTCA-3' to 5'-AGAGCA-3', and the resultant mutated DNA was subcloned into pGL4.20 vector, termed pUSP19-mhERE. C2C12 myoblasts were cultured in steroid-free differentiation medium, which was composed of phenol red-free DMEM supplemented with $2 \% \mathrm{v} / \mathrm{v}$ dextran-coated charcoal-stripped horse serum, on 48-well plates, and transiently transfected with each reporter vector using HilyMax (Dojindo, Kumamoto, Japan) for $24 \mathrm{~h}$, and incubated in fresh medium containing $10 \mathrm{nmol} / \mathrm{l} \mathrm{E}_{2}$ for an additional $24 \mathrm{~h}$. Luciferase activity was determined as described previously (Higashimura et al. 2011). Transfection efficiency was normalized with Renilla luciferase expression vector (pGL4.73[hRluc/SV40]; Promega), and data were expressed as relative light units (RLU, firefly luciferase activity divided by Renilla luciferase activity).

\section{In vivo siRNA-mediated knockdown}

Murine USP19 siRNA (siUSP19), murine ER $\alpha$ siRNA $(\operatorname{siER} \alpha)$, and control siRNA (siCTL; catalog number
S21-25P) were purchased from Koken (Tokyo, Japan). The sequences of siUSP19 and $\operatorname{siER} \alpha$ were described previously (Ogawa et al. 2011). siUSP19 or siER $\alpha$ was transfected to the right hindlimb muscle, and control siRNA was transfected to the left hindlimb muscle using atelocollagen (AteloGene Local Use; Koken) at 8 weeks of age ( $n=5$ per sex). Atelocollagen complexed with siRNA was prepared as follows: $0.05 \% \mathrm{w} / \mathrm{v}$ atelocollagen was mixed with an equal volume of siRNA solution $(10 \mu \mathrm{mol} / \mathrm{l})$. The hindlimb was injected with $100 \mu \mathrm{l}$ atelocollagen-siRNA complex at multiple sites. After 1 week, mice were sacrificed by exsanguination under anesthesia. The soleus muscles were isolated, weighed, frozen in liquid nitrogen, and stored at $-80^{\circ} \mathrm{C}$ until use.

\section{In vitro siRNA-mediated knockdown}

Murine $\operatorname{ER} \alpha(\operatorname{siER} \alpha)$ and control siRNA (siCTL) were purchased from Sigma-Aldrich as described previously (Ogawa et al. 2011). The siRNA duplexes at concentrations of $10 \mathrm{nM}$ were introduced into C2C12 myotubes using Lipofectamine RNAiMAX reagent and Opti-MEM (Invitrogen). After siRNA treatment for $6 \mathrm{~h}$, culture medium was replaced by fresh steroid-free differentiation medium.

\section{Histological analysis and morphometric measurements}

Soleus muscles were dissected from female and male mice ( $n=5$ per hindlimb), immediately fixed in $10 \%$ formalin, embedded in paraffin, sectioned at $4 \mu \mathrm{m}$, and stained with hematoxylin and eosin. Images of the muscle sections were obtained with a BIOREVO BZ-9000 microscope (Keyence, Osaka, Japan). The cross-sectional area (CSA) $\left(\mu \mathrm{m}^{2}\right)$ of muscle fibers was measured using ImageJ software (version 1.44p; National Institutes of Health, Bethesda, MD, USA). Mean fiber CSA was determined from approximately 250 fibers per soleus muscle.

\section{Serum $E_{2}$ measurement}

Blood was collected from female and male mice $(n=5$ per sex) and incubated at $37^{\circ} \mathrm{C}$. After $1 \mathrm{~h}$, serum was separated by centrifugation at $3000 \boldsymbol{g}$ for $10 \mathrm{~min}$. $\mathrm{E}_{2}$ was extracted from serum using hexane-ethyl acetate (3:2 by volume). The organic extract containing $\mathrm{E}_{2}$ was dried under $\mathrm{N}_{2}$ gas and dissolved in methanol. Serum $\mathrm{E}_{2}$ levels were measured using an estradiol ELISA kit (Tokiwa Chemical Industries, Tokyo, Japan).

Published by Bioscientifica Ltd. 


\section{RNA isolation and quantitative RT-PCR analysis}

Total RNA was isolated from soleus muscle ( $n=5$ per sex) using Sepasol-RNA I Super G (Nacalai Tesque, Kyoto, Japan), and reverse-transcribed. The resultant cDNAs were subjected to quantitative PCR (qPCR) using the following specific primers: Usp19 (forward primer 5'-GCGGCACAAGATGAGAAATG-3' and reverse primer $5^{\prime}$-ACCAGGAACTTGATGGGCTT-3'), $E R \alpha$ (forward primer 5'-ATGATTGGTCTCGTCTGGCGCT-3' and reverse primer 5'-AGCAGGTCATAGAGGGGCACAACG-3'), and peptidylprolyl isomerase A (Ppia) (forward primer $5^{\prime}$-GCAAATGCTGGACCAAACAC- $3^{\prime}$ and reverse primer $5^{\prime}$-TCACCTTCCCAAAGACCACAT- $\left.3^{\prime}\right)$. The PCR profiles consisted of denaturation at $95^{\circ} \mathrm{C}$ for $1 \mathrm{~min}$, primer-annealing at $57^{\circ} \mathrm{C}$ for $1 \mathrm{~min}$, and primer extension at $72^{\circ} \mathrm{C}$ for $30 \mathrm{~s}$. The final primer extension was performed at $72{ }^{\circ} \mathrm{C}$ for $10 \mathrm{~min}$. The PCR in qPCR was performed with a Plexor One-Step qRT-PCR System (Promega) on a Thermal Cycler Dice, TP-800 (Takara Bio, Shiga, Japan). Ct values were transformed into relative quantification data by the $2^{-\Delta \Delta C t}$ method. The Ct value of Ppia was used as an internal control (Nishimura et al. 2008).

\section{Western blotting}

Soleus muscle from male and female mice $(n=3$ per hindlimb) was homogenized in lysis buffer $(50 \mathrm{mmol} / \mathrm{l}$ Tris- $\mathrm{HCl}$, pH 7.5, containing $150 \mathrm{mmol} / \mathrm{l} \mathrm{NaCl}, 0.25 \% \mathrm{w} / \mathrm{v}$ sodium deoxycholate, $1 \% \mathrm{w} / \mathrm{v}$ NP-40, $0.1 \% \mathrm{w} / \mathrm{v}$ SDS, $1 \mathrm{mmol} / 1$ EDTA, $25 \mathrm{mmol} / 1 \mathrm{NaF}, 1 \mathrm{mmol} / \mathrm{l} \mathrm{Na}_{3} \mathrm{VO}_{4}$, $1 \mathrm{mmol} / \mathrm{l}$ 4-(2-aminoethyl) benzenesulfonyl fluoride, $10 \mu \mathrm{g} / \mathrm{ml}$ leupeptin, and $1 \mu \mathrm{g} / \mathrm{ml}$ aprotinin). The homogenates were subjected to SDS-PAGE and analyzed by western blotting with mouse monoclonal antiubiquitin IgG (FK2; Nippon Biotest Laboratories, Tokyo, Japan). Immunoreactive proteins were incubated with HRP-conjugated goat anti-mouse IgG and reacted with Immobilon Western Chemiluminescent HRP Substrate (Millipore, Billerica, MA, USA), followed by detection with an ImageQuant LAS 4000 imaging system (GE Healthcare, Uppsala, Sweden). The levels of ubiquitin conjugates were quantified by densitometry using ImageJ software.

\section{Chromatin immunoprecipitation assay}

C2C12 myotubes were incubated in steroid-free differentiation medium containing $10 \mathrm{nmol} / 1 \mathrm{E}_{2}$ for $30 \mathrm{~min}$, followed by fix with $1 \%$ paraformaldehyde. The frozen skeletal muscle tissues were crushed, followed by incubation with $1 \% \mathrm{w} / \mathrm{v}$ paraformaldehyde. Cells were lysed, and tissues were homogenized in SDS-lysis buffer $(50 \mathrm{mmol} / \mathrm{l}$ Tris- $\mathrm{HCl}, \mathrm{pH} 8.0$, containing $1 \% \mathrm{w} / \mathrm{v}$ SDS, $10 \mathrm{mmol} / \mathrm{l} \mathrm{EDTA}, 1 \mathrm{mmol} / \mathrm{l}$ 4-(2-aminoethyl) benzenesulfonyl fluoride, $10 \mu \mathrm{g} / \mathrm{ml}$ leupeptin, and $1 \mu \mathrm{g} / \mathrm{ml}$ aprotinin) as described previously (Higashimura et al. 2011). In brief, lysates and homogenates were sonicated (Handy Sonic UR-21P; Tomy Seiko, Tokyo, Japan) to shear the DNA, followed by centrifugation at $20000 \boldsymbol{g}$ for $3 \mathrm{~min}$. The supernatant was diluted tenfold with chromatin immunoprecipitation (ChIP) dilution buffer and pre-cleared with $40 \mu \mathrm{l}$ of protein G-Sepharose resin $(50 \% \mathrm{w} / \mathrm{v}$ slurry; GE Healthcare) for $1 \mathrm{~h}$ at $4{ }^{\circ} \mathrm{C}$. The supernatant was reacted with rabbit polyclonal anti-ER $\alpha$ (MC20; Santa Cruz Biotechnology) or control IgG overnight at $4{ }^{\circ} \mathrm{C}$ and incubated with $40 \mu$ l of protein G-Sepharose resin $(50 \%$ $\mathrm{w} / \mathrm{v}$ slurry) for $1 \mathrm{~h}$. The resin was sequentially washed. Immunoprecipitated complexes with anti-ER $\alpha$ or control IgG were eluted with elution buffer. Immunoprecipitated DNA was analyzed by qPCR. Primers used for qPCR were as follows: forward primer $5^{\prime}$-TGAGTGGTGTGGGCCTCAAGTC-3' and reverse primer 5'-TAGCATAACGGCTCGGTCGGCA-3'. The PCR in qPCR was performed, and $C t$ values were obtained as previously described. Signals obtained from the ChIP sample were divided by signals obtained from an input sample and expressed as relative values.

\section{Statistical analysis}

The significance of difference between two groups was determined with Student's $t$-test. One-way ANOVA with Tukey's post hoc testing was used in experiments that had three or more groups. Statistical analysis was performed using JMP statistical software version 8.0.1 (SAS Institute, Cary, NC, USA). Data are expressed as means \pm s.D., and differences were considered statistically significant at $P$ values $<0.05$.

\section{Results}

USP19 knockdown increases the mass and size of soleus muscle in female mice

In soleus muscle, Usp19 mRNA levels were significantly higher in female mice than in male mice (Fig. 1A). To address the role of USP19 in the soleus muscle mass, USP19 siRNA was transfected into soleus muscle of male and female mice. The mRNA expression of Usp19 was knocked down in soleus muscle (Fig. 1B). Knockdown of USP19

Published by Bioscientifica Ltd. 
A

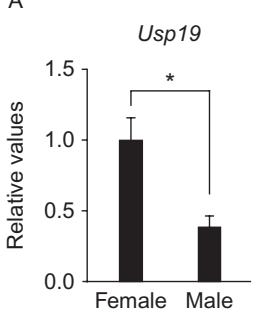

B
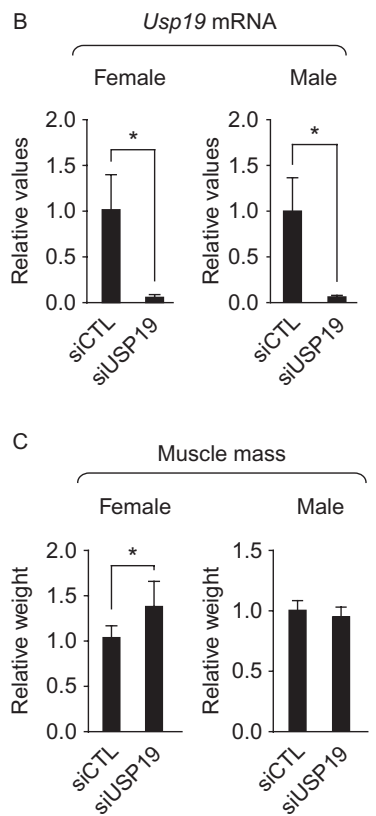

D

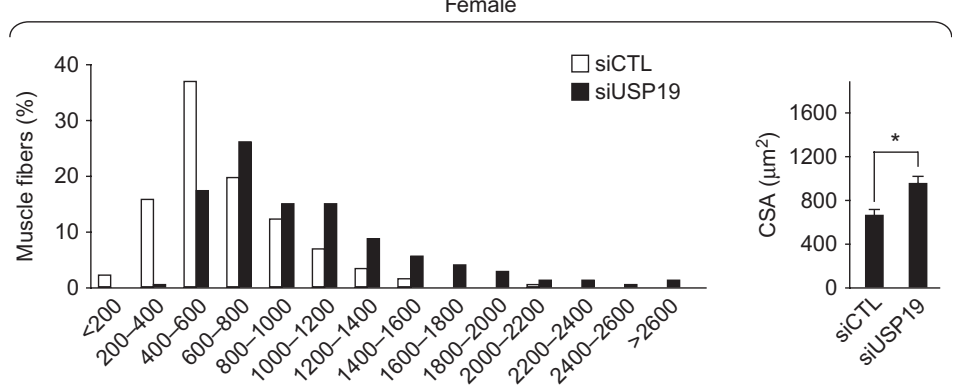

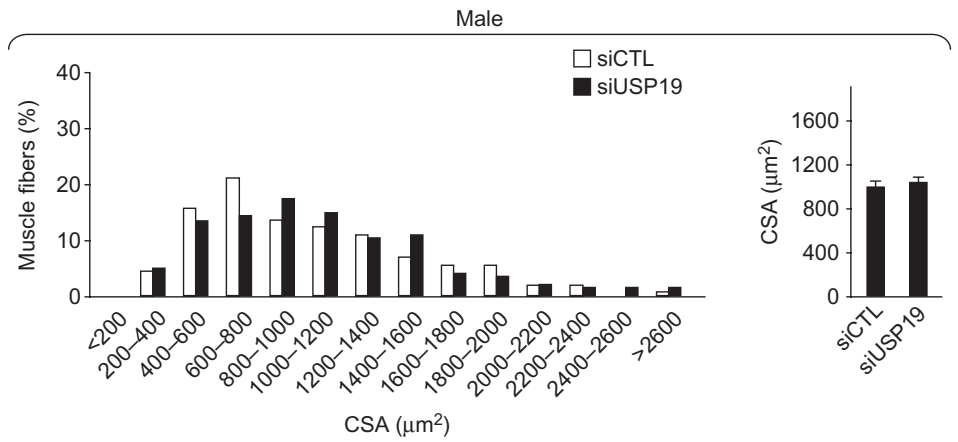

\section{Figure 1}

Effects of USP19 on skeletal muscle mass and muscle fiber CSA in female mice. (A) Usp19 mRNA levels were normalized with Ppia mRNA level in soleus muscles in female and male mice, and relative values are indicated. (B, C, and D) USP19 siRNA (siUSP19) and control siRNA (siCTL) were transduced into right and left hindlimbs, respectively, in female and male

increased the mass of the soleus muscle in females, but not in males (Fig. 1C). Furthermore, to determine the effect of USP19 expression on size of muscle fiber, the CSA of each muscle fiber was quantitated. In females and males, the frequency distribution of CSA of fibers was shifted toward larger sizes in USP19 siRNA-treated soleus muscle than in control siRNA-treated soleus muscle, but knockdown of USP19 significantly increased the CSA of soleus muscle fiber only in females (Fig. 1D). These results indicate that USP19 represses the mass and size of soleus muscle only in female mice.

\section{$E_{2}$ induces the binding of ER $\alpha$ to half-ERE in Usp19 gene in $\mathrm{C} 2 \mathrm{C} 12$ myoblasts}

Intron 1 of Usp19 was found to contain one potential half-ERE (hERE) by rVISTA (Loots et al. 2002). To evaluate whether it is functional, we constructed two luciferase reporter vectors composed of the nucleotide sequence from -152 to +1902 , one with authentic hERE sequence and the other with the mutated hERE (mhERE) sequence (Fig. 2A), and termed pUSP19-hERE mice. (B) In soleus muscles, Usp19 mRNA levels were normalized with Ppia mRNA level. (C) Wet soleus muscle weights were divided by body weights, and relative values are indicated. (D) CSA of soleus muscles was determined. Values are indicated as means \pm S.D. $(n=5)$, and statistically significant differences are indicated by asterisk ( $P<0.05$ by Student's $t$-test).

and pUSP19-mhERE, respectively. $\mathrm{E}_{2}$ increased luciferase activity in the pUSP19-hERE-transfected cells, but not in the pUSP19-mhERE-transfected cells (Fig. 2B), and the increase was abolished by ER $\alpha$ knockdown (Fig. 2C). In a ChIP assay, ER $\alpha$ bound to hERE only in the presence of $\mathrm{E}_{2}$ (Fig. 2D). These results indicate that the hERE in intron 1 of Usp19 gene is functional and that $\mathrm{E}_{2}$ promotes the binding of ER $\alpha$ to hERE in Usp19 gene.

\section{ER $\alpha$ is recruited to hERE in Usp19 gene in soleus muscle in females}

In soleus muscle, the expression levels of $E R \alpha$ were similar between female and male mice (Fig. 3A). A ChIP analysis showed that ER $\alpha$ bound to hERE in Usp19 in soleus muscle in female mice, but not in male mice (Fig. 3B). Furthermore, ER $\alpha$ did not bind to hERE in Usp19 gene in OVX female mice, whereas ER $\alpha$ was recruited to hERE when OVX mice were injected with $\mathrm{E}_{2}$ (Fig. 3C). In male mice, administration of $\mathrm{E}_{2}$ increased the mRNA levels of Usp19 in soleus muscle (Fig. 3D) and decreased the mass of soleus muscle (Fig. 3E). $\mathrm{E}_{2}$ resulted in the recruitment

Published by Bioscientifica Ltd. 
A
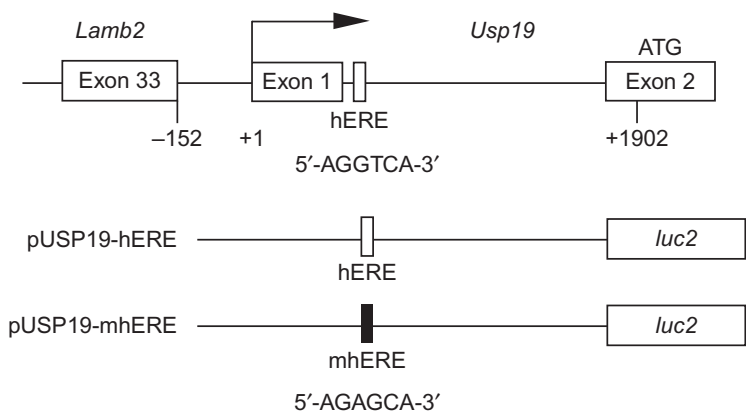

Figure 2

Identification of the ER $\alpha$-binding site in intron 1 of Usp19. (A) A putative site for a hERE in Usp19 is represented. The reporter vector containing hERE sequence (5'-AGGTCA-3') or mhERE (5'-AGAGCA-3') sequence was constructed. (B) C2C12 cells were transfected with reporter vector (pUSP19hERE or pUSP19-mhERE) and further incubated in steroid-free differentiation medium in the presence or absence of $E_{2}$. The luciferase activity was determined. (C) $\mathrm{C} 2 \mathrm{C} 12$ cells were transfected with control siRNA (siCTL) or ER $\alpha$ siRNA (siER $\alpha$ ), followed by further transfection with pUSP19-hERE.

of $\mathrm{ER} \alpha$ to hERE in male mice (Fig. 3F). Serum $\mathrm{E}_{2}$ concentration was decreased by ovariectomy and restored by administration of $\mathrm{E}_{2}$ (Fig. $3 \mathrm{G}$ ). $\mathrm{E}_{2}$ concentration in male mice was similar to that in OVX female mice, but was increased to that in female mice by $\mathrm{E}_{2}$ administration. These results indicate that ER $\alpha$ is recruited to hERE in Usp19 in soleus muscle only in female mice in an $\mathrm{E}_{2}$-dependent manner under physiological conditions.

\section{ER $\alpha$ knockdown increases soleus muscle mass by repressing USP19 expression in female mice}

To address the role of ER $\alpha$ in skeletal muscle mass, $\mathrm{ER} \alpha$ siRNA was transfected into skeletal muscle. ER $\alpha$ siRNA specifically knocked down the expression of $E R \alpha$ mRNA in soleus muscle of male and female mice (Fig. 4A). Knockdown of ER $\alpha$ decreased the expression level of Usp19 mRNA in soleus muscle only in female mice (Fig. 4B). Furthermore, knockdown of ER $\alpha$ increased the mass of soleus muscle only in female mice (Fig. 4C). These results indicate that in females, a decrease in ER $\alpha$ increases the mass of soleus muscle by down-regulating USP19 expression.

\section{USP19 and $E_{2}$ are involved in the levels of ubiquitin conjugates}

We determined whether USP19 regulates the levels of ubiquitin conjugates in soleus muscle under physiological conditions. In soleus muscle transfected with control siRNA, the levels of ubiquitin conjugates were not
B

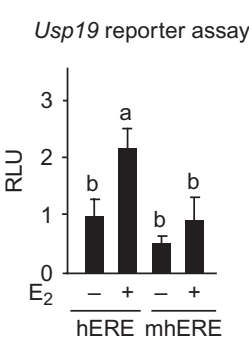

C

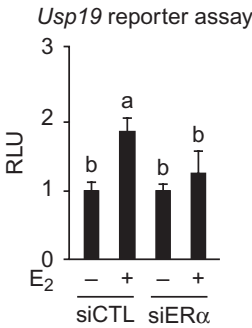

D

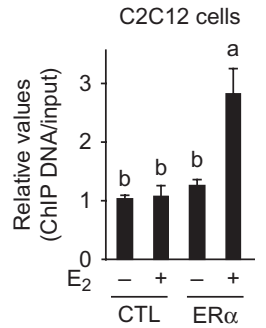

Cells were incubated in steroid-free differentiation medium in the presence or absence of $E_{2}$, and the luciferase activity was determined. (D) C2C12 cells were cultured in steroid-free differentiation medium in the present or absence of $E_{2}$. The protein-DNA complexes were cross-linked and immunoprecipitated with control (CTL) IgG or anti-ER $\alpha(E R \alpha) \lg$. Immunoprecipitated DNA was analyzed by qPCR. (B, C, and D). Values are indicated as means \pm s.D. $(n=3)$, and bars not sharing a common letter are significantly different ( $P<0.05$ by one-way ANOVA with Tukey's test).

significantly different between females and males (Fig. 5A). However, knockdown of USP19 resulted in increased levels of ubiquitin conjugates in females, but not in males. Furthermore, OVX increased the levels of ubiquitin conjugates, and administration of $\mathrm{E}_{2}$ restored OVX-increased levels of ubiquitin conjugates (Fig. 5B). These results indicate that USP19 contributes to deubiquitination reaction in an $\mathrm{E}_{2}$-dependent manner in females, but not in males.

\section{Discussion}

Sex hormones contribute to the sex differences in body weight and composition between men and women. Although there are sex-related differences in gene expression in human skeletal muscle (Deasy et al. 2008, Welle et al. 2008), the molecular mechanisms underlying the quantitative difference between male and female skeletal muscles remain largely unknown. In this study, we demonstrate that USP19 is a potent down-regulator of muscle mass in young female mice.

Knockdown of USP19 increased the muscle mass only in young female mice under normal physiological conditions (Fig. 1C). Skeletal muscle mass and muscle proteins are decreased under pathophysiological conditions such as fasting, diabetes, cancer, and disuse (Bonaldo \& Sandri 2013). Muscle atrophy induces the expression of atrophy-related genes (atrogenes) such as muscle-specific $E_{3}$ ubiquitin ligases (MAFbx/atrogin-1 and MuRF1) (Bodine et al. 2001). The expression of USP19 is increased in skeletal muscle atrophying in response to

Published by Bioscientifica Ltd. 
A

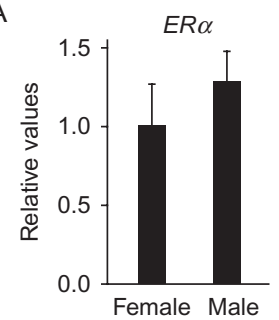

C

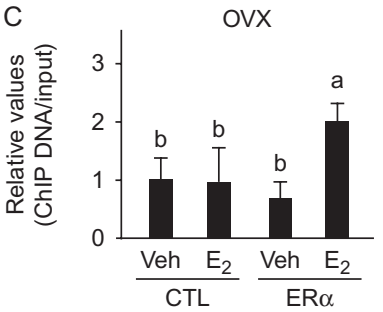

E

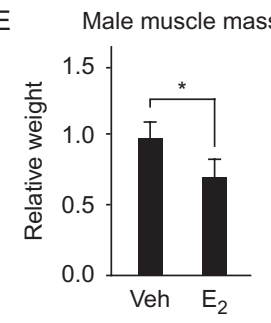

G

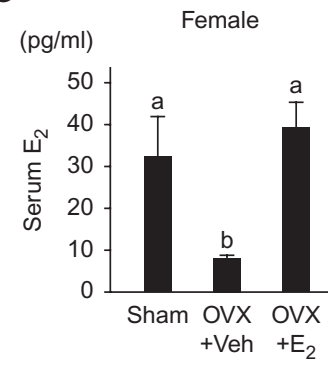

B

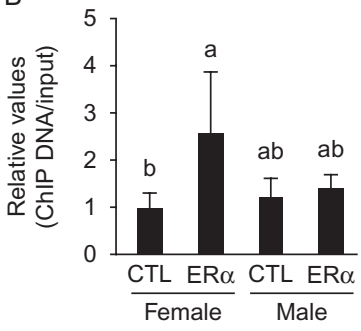

D

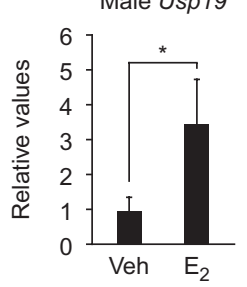

F
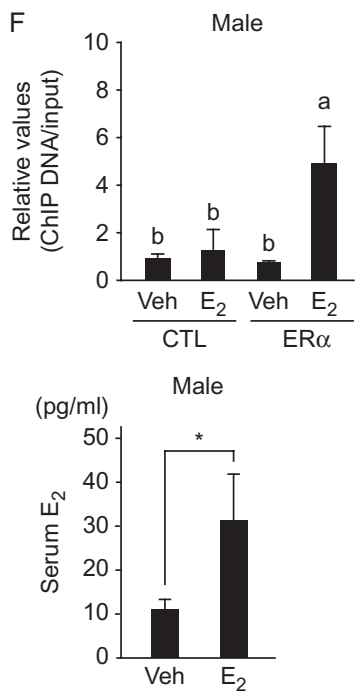

Figure 3

Recruitment of ER $\alpha$ to a half-ERE in Usp19 gene in skeletal muscle. (A) $E R \alpha$ mRNA levels were normalized with Ppia mRNA levels in soleus muscles of female and male mice. (B) The protein-DNA complexes were prepared from the soleus muscles and immunoprecipitated with control (CTL) IgG or anti-ER $\alpha(E R \alpha)$ IgG. Immunoprecipitated DNA was analyzed by qPCR. (C) The protein-DNA complexes were prepared from the soleus muscles in OVX mice injected with vehicle (Veh) or $E_{2}$, and immunoprecipitated with control (CTL) IgG or anti-ER $\alpha(E R \alpha)$ IgG. Immunoprecipitated DNA was analyzed by qPCR. (D) Usp19 mRNA levels were normalized with Ppia mRNA levels in soleus muscles of male mice injected with vehicle (Veh) or $E_{2}$. (E) Wet soleus muscle weights were divided by body weights in male mice injected with vehicle (Veh) or $E_{2}$. (F) The protein-DNA complexes were prepared from the soleus muscles in male mice injected with vehicle (Veh) or $E_{2}$ and immunoprecipitated with control (CTL) IgG or anti-ER $\alpha(E R \alpha) \lg$. Immunoprecipitated DNA was analyzed by qPCR. (G) Serum $E_{2}$ concentrations were determined in sham-operated or OVX female mice and male mice. OVX female mice and male mice were injected with vehicle (Veh) or $\mathrm{E}_{2}$. Data were indicated as means \pm s.D. $(n=5)$. Bars not sharing a common letter are significantly different $(P<0.05$ by one-way ANOVA with Tukey's test), and statistically significant differences are indicated by asterisk ( ${ }^{*} P<0.05$ by Student's $t$-test).

fasting, diabetes, dexamethasone treatment, cancer, and denervation in male rodents (Combaret et al. 2005, Ogawa et al. 2013). Furthermore, administration of $\mathrm{E}_{2}$ to OVX mice increases USP19 expression to the control level and decreases the mass of soleus muscle (Ogawa et al. 2011). These show that USP19 is an atrophy-related gene. On the other hand, with respect to myogenesis, overexpression of USP19 decreases the expression levels of myofibrillar proteins in $\mathrm{C} 2 \mathrm{C} 12$ myoblasts and represses myogenesis, whereas depletion of USP19 increases the expression level of myogenin, which is the myogenic transcriptional factor, and promotes the synthesis of myofibrillar proteins (Ogawa et al. 2011). Furthermore, in C2C12 myoblasts, $\mathrm{E}_{2}$ increases USP19 expression and represses myogenesis, whereas knockdown of USP19 restores $\mathrm{E}_{2}$-decreased levels of myofibrillar proteins (Ogawa et al. 2011). Three conclusions can be drawn from these results: USP19 acts as i) a negative regulator of muscle mass in young female mice under normal physiological conditions; ii) a negative regulator of muscle mass in male mice, and perhaps also in female mice, under pathophysiological conditions; iii) a repressor of myogenesis.

Cellular responses to $\mathrm{E}_{2}$ are elicited through genomic and non-genomic mechanisms. Genomic mechanisms refer to the transcriptional activation of target genes through the binding of ERs (ER $\alpha$ and $\mathrm{ER} \beta$ ) to palindromic EREs of their target gene promoters in the nucleus (Hewitt $\&$ Korach 2002). Besides palindromic EREs, ER $\alpha$ or ER $\beta$ regulates the expression of prothymosin (Martini \& Katzenellenbogen 2001), cathepsin D (Wang et al. 1997), ovalbumin (Kato et al. 1992), and progesterone receptor (Petz \& Nardulli 2000) through binding to hEREs. Nongenomic mechanisms refer to rapid cellular responses (e.g., calcium mobilization, kinase activation, and nitric oxide production) induced not only by extranuclear ERs but also by a membrane-associated G-protein-coupled receptor known as GPR30 (Prossnitz et al. 2008). These responses occur on a timescale of seconds to minutes, whereas the genomic responses occur on a timescale of hours. $E_{2}$ increases USP19 expression through ER $\alpha$ during myogenesis (Ogawa et al. 2011). ER $\alpha$ bound to a hERE in intron 1 of Usp19 gene in an $\mathrm{E}_{2}$-dependent manner in C2C12 cells (Fig. 2D) and in muscles of OVX mice (Fig. 3C), indicating that the genomic response of ER $\alpha$ regulates USP19 expression in an $\mathrm{E}_{2}$-dependent manner. Furthermore, knockdown of ER $\alpha$ decreased the USP19 expression (Fig. 4B) and increased the mass in the soleus muscle (Fig. 4C) in females under physiological conditions. Therefore, these results indicate that the

Published by Bioscientifica Ltd. 
A

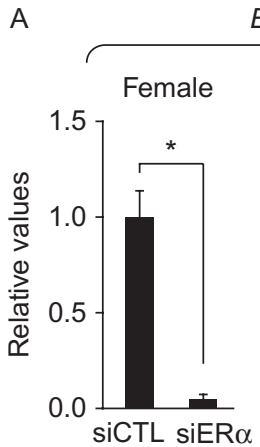

$E R \alpha$

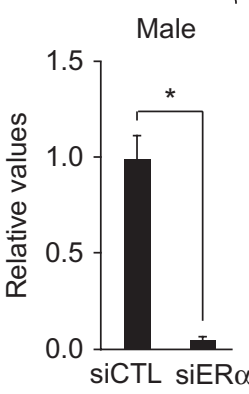

B

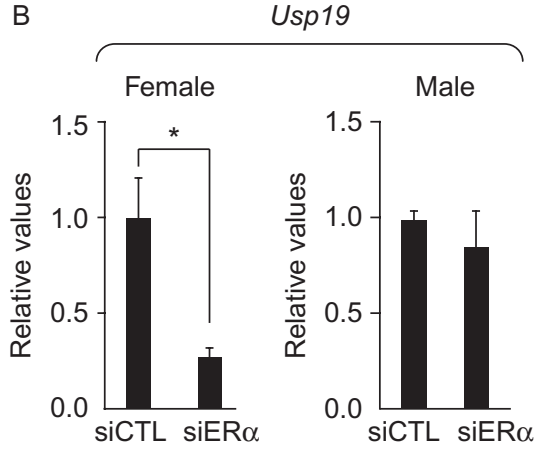

C

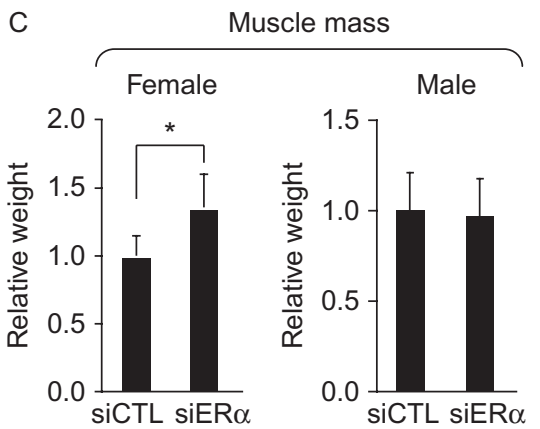

Figure 4

Involvement of ER $\alpha$ and USP19 in soleus muscle mass in female mice. ER $\alpha$ siRNA (siER $\alpha$ ) and control siRNA (siCTL) were transduced into right and left hindlimbs, respectively, in female and male mice. (A) ER mRNA level was normalized with Ppia mRNA level in soleus muscles in female and male mice. (B) Usp19 mRNA level was normalized with Ppia mRNA level in soleus muscle. (C) Wet soleus muscle weights were divided by body weights. Values are indicated as means \pm s.D. $(n=5)$, and statistically significant differences are indicated by asterisk ( ${ }^{*} P<0.05$ by Student's $t$-test).

expression of USP19 is regulated by ER $\alpha$ in the soleus muscle under physiological conditions.

Knockdown of USP19 induced hypertrophy in skeletal muscle of young female mice (Fig. 1D). After birth, skeletal muscle mass primarily increases by hypertrophy in muscle fiber (Ontell et al. 1984, White et al. 2010). Muscle hypertrophy occurs when the overall rate of protein synthesis exceeds the rate of protein degradation. Increases in protein degradation are involved in the loss of skeletal muscle mass. The ubiquitin-proteasome system contributes to the majority of protein degradation. During muscle atrophy, the expression of MAFbx/atrogin-1 and MuRF1 is upregulated and promotes ubiquitination of proteins (Bodine et al. 2001, Bonaldo \& Sandri 2013). In functional overload model mice, depletion of MAFbx/ atrogin-1, but not MuRF1, attenuates overload-induced growth in plantaris muscle only in females (Baehr et al. 2014). MAFbx/atrogin-1 mediates ubiquitination of MyoD and eIF3-f (Tintignac et al. 2005, Csibi et al. 2008), and
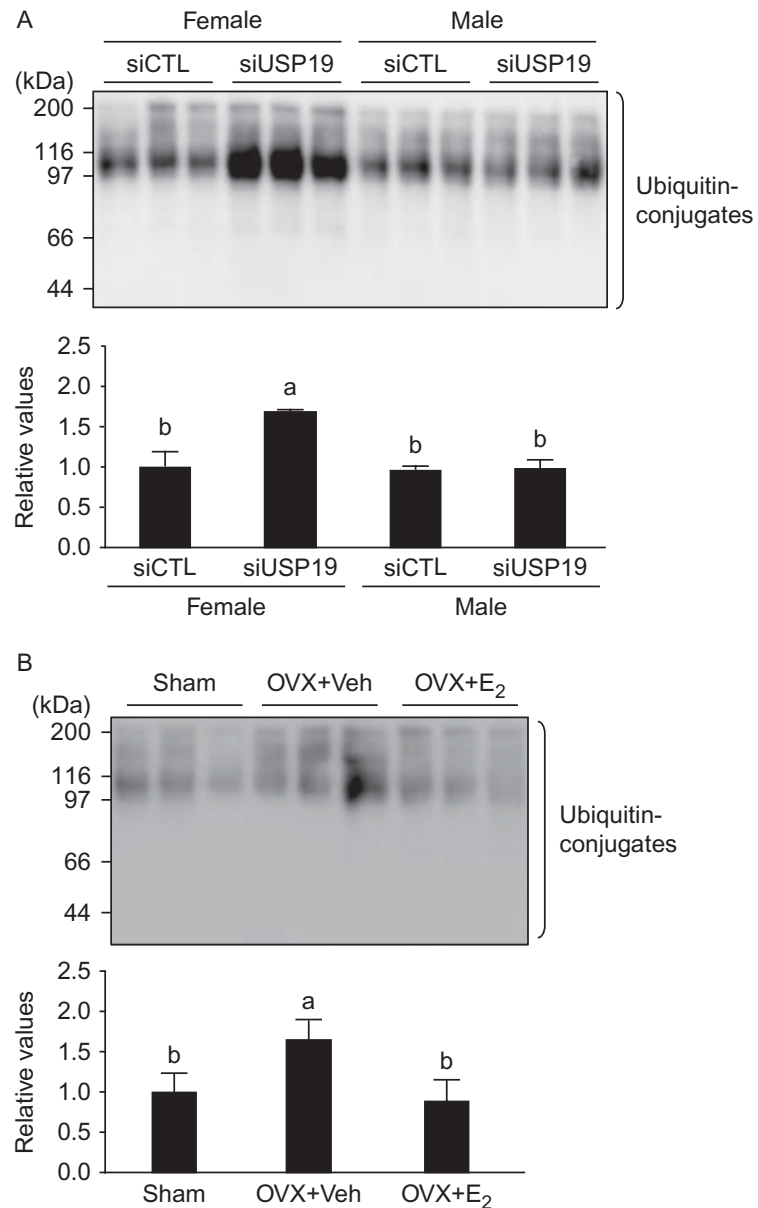

Figure 5

Involvement of USP19 and $E_{2}$ in the levels of ubiquitin conjugates. (A) (Upper panel) USP19 siRNA (siUSP19) and control siRNA (siCTL) were transduced into right and left hindlimbs, respectively, in female and male mice, and homogenates from soleus muscles were analyzed by western blotting with anti-ubiquitin antibody. (Lower panel) Band intensities were calculated by densitometry. (B) (Upper panel) Soleus muscles were isolated from sham mice (Sham) and OVX mice treated with vehicle (OVX + Veh) or $E_{2}\left(O V X+E_{2}\right)$ and homogenated. Western blot analysis was performed with anti-ubiquitin antibody. ( $A$ and $B$ ) (Lower panel) Band intensities were calculated by densitometry. Data were indicated as means \pm s.D. $(n=3)$, and bars not sharing a common letter are significantly different $(P<0.05$ by one-way ANOVA with Tukey's test). 


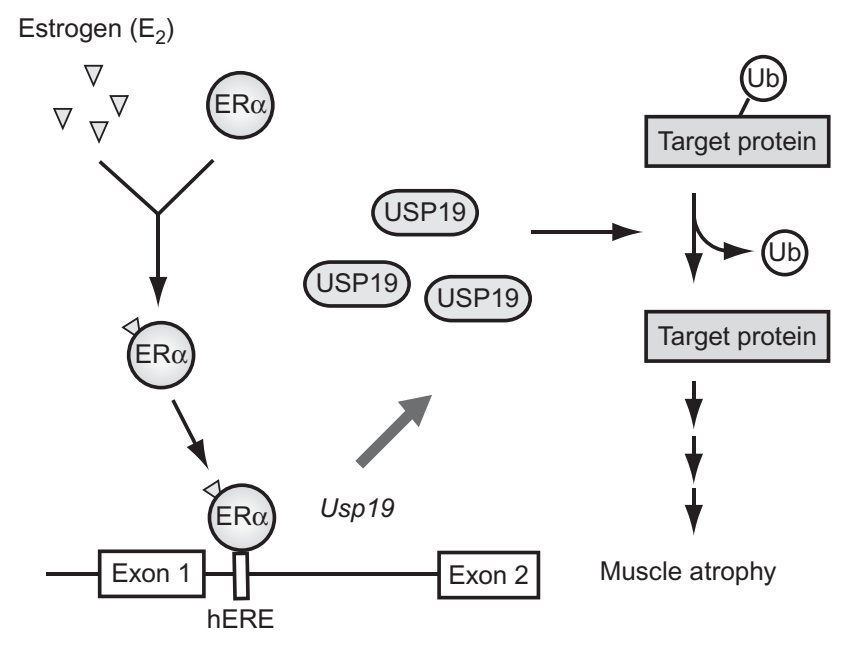

Figure 6

A schematic showing association between ER $\alpha$-mediated USP19 expression and skeletal muscle mass. $E_{2}$-bound ER $\alpha$ binds to hERE in intron 1 of Usp19 and upregulates Usp19 expression. USP19 removes ubiquitin from ubiquitinated target proteins, resulting in skeletal muscle atrophy in young female mice.

MuRF1 contributes to ubiquitination of troponin I, $\beta /$ slow myosin heavy chain, myosin heavy chain IIa, and actin (Kedar et al. 2004, Fielitz et al. 2007, Polge et al. 2011). These results suggest that the quantity and quality of ubiquitinated proteins are different between males and females although they may depend on the situations, such as when the mice are subjected to a functional overload. In the present study, there was no significant difference of ubiquitin conjugates between females and males under physiological conditions, whereas knockdown of USP19 resulted in higher levels of ubiquitin conjugates in females than in males (Fig. 5). In addition, USP19 depletion had no effect on muscle mass and size in male mice under physiological conditions (Fig. 1C and D). USP14 seems to remove and recycle ubiquitin from non-specific ubiquitinconjugated proteins on the proteasome because USP14 is associated with the proteasome (Peth et al. 2009). In contrast, USP19 appears to remove ubiquitin from specific ubiquitin-conjugated substrate proteins and protect them from proteasomal degradation because it does not appear to be associated with the proteasome (Sundaram et al. 2009). Instead, USP19 is associated with several proteins, such as cellular inhibitors of apoptosis (cIAP1 and cIAP2) (Mei et al. 2011), endoplasmic-reticulum-associated degradation substrates (Hassink et al. 2009) and heat shock protein 90 (Lee et al. 2014). These results suggest that, under normal physiological conditions, USP19 substrate proteins regulating muscle mass are weakly expressed or weakly ubiquitinated in male mice.
In contrast, administration of $\mathrm{E}_{2}$ to male mice resulted in an increased USP19 expression and a decreased soleus muscle mass (Fig. 3D). Sex hormones are involved in the differential regulation of gene expression in human skeletal muscle cells (Deasy et al. 2008, Welle et al. 2008). This, together with the present results, suggest that the USP19 substrate proteins regulating muscle mass are ubiquitinated or expressed in an $\mathrm{E}_{2}$-dependent manner.

Systematic ER $\alpha$ knockout decreases the soleus muscle mass normalized to body mass, and total protein and myosin content are similar between systematic ER $\alpha$ knockout mice and WT mice that are 5-8 months old (Brown et al. 2009). Furthermore, in aged (4 months of age) OVX female mice, $E_{2}$ replacement improves OVXinduced declines in hindlimb muscle contractility (Moran et al. 2007). These results are contradictory to our finding that in young female mice ( 8 weeks of age), knockdown of $\mathrm{ER} \alpha$ increased soleus muscle mass normalized to body mass (Fig. 4C). The contradictory results regarding the effects of $E_{2}$ on skeletal muscle mass may be due to the difference in age of mice used in each study. We are presently attempting to study the effects of $E_{2}$ on skeletal muscle mass in aged females.

In conclusion, in young female mice, the knockdown of USP19 resulted in an increase in soleus muscle mass, and ER $\alpha$ increased the levels of USP19 at the transcriptional level (Fig. 6). These results indicate that USP19 is a potent down-regulator of muscle mass in young female mice. Identification of the substrate proteins of USP19 should elucidate the sex-specific regulation of skeletal muscle mass in young females.

\section{Declaration of interest}

The authors declare that there is no conflict of interest that could be perceived as prejudicing the impartiality of the research reported.

\section{Funding}

This work was supported by Grant-in-Aid (13J10847) for JSPS Fellows (to M O) and Grant-in-Aids (23580182 and 26292073) for scientific research (to $R$ Y) from the Japan Society for the Promotion of Science and by Grant-in-Aid for Linkage Project between Different Fields (to $R Y$ ) from Osaka Prefecture University.

\section{Author contributions statement}

$\mathrm{M} \mathrm{O}$ and $\mathrm{R} Y$ conceived and designed the research; $\mathrm{MO}$ and T K performed experiments; $\mathrm{M} \mathrm{O}, \mathrm{T} \mathrm{K}$, and $\mathrm{N} \mathrm{H}$ analyzed data; $\mathrm{M} \mathrm{O}$ and $\mathrm{R} \mathrm{Y}$ interpreted data; $M O$ prepared figures; $\mathrm{M} \mathrm{O}$ and $\mathrm{R} Y$ drafted manuscript; $\mathrm{M} \mathrm{O}, \mathrm{TK}, \mathrm{N} \mathrm{H}$, and $\mathrm{R}$ Y edited manuscript; $\mathrm{M} \mathrm{O}, \mathrm{TK}, \mathrm{N} \mathrm{H}$, and $\mathrm{R} Y$ approved final version of manuscript.

Published by Bioscientifica Ltd. 


\section{Acknowledgements}

We are very grateful to Shintaro Ono and Tomotaka Sakamoto for helpful support of animal experiments.

\section{References}

Abmayr SM \& Pavlath GK 2012 Myoblast fusion: lessons from flies and mice. Development 139 641-656. (doi:10.1242/dev.068353)

Baehr LM, Tunzi M \& Bodine SC 2014 Muscle hypertrophy is associated with increases in proteasome activity that is independent of MuRF1 and MAFbx expression. Frontiers in Physiology 5 69. (doi:10.3389/fphys. 2014.00069)

Barros RP, Machado UF, Warner M \& Gustafsson JA 2006 Muscle GLUT4 regulation by estrogen receptors ER $\beta$ and ER $\alpha$. PNAS 103 1605-1608. (doi:10.1073/pnas.0510391103)

Bergeron R, Russell RR III, Young LH, Ren JM, Marcucci M, Lee A \& Shulman GI 1999 Effect of AMPK activation on muscle glucose metabolism in conscious rats. American Journal of Physiology 276 E938-E944.

Bodine SC, Latres E, Baumhueter S, Lai VK, Nunez L, Clarke BA, Poueymirou WT, Panaro FJ, Na E, Dharmarajan K et al. 2001 Identification of ubiquitin ligases required for skeletal muscle atrophy. Science 294 1704-1708. (doi:10.1126/science.1065874)

Bonaldo P \& Sandri M 2013 Cellular and molecular mechanisms of muscle atrophy. Disease Models \& Mechanisms 6 25-39. (doi:10.1242/dmm. 010389)

Brown M, Ning J, Ferreira JA, Bogener JL \& Lubahn DB 2009 Estrogen receptor- $\alpha$ and $-\beta$ and aromatase knockout effects on lower limb muscle mass and contractile function in female mice. American Journal of Physiology. Endocrinology and Metabolism 296 E854-E861. (doi:10.1152/ ajpendo.90696.2008)

Combaret L, Adegoke OA, Bedard N, Baracos V, Attaix D \& Wing SS 2005 USP19 is a ubiquitin-specific protease regulated in rat skeletal muscle during catabolic states. American Journal of Physiology. Endocrinology and Metabolism 288 E693-E700. (doi:10.1152/ajpendo.00281.2004)

Csibi A, Tintignac LA, Leibovitch MP \& Leibovitch SA 2008 eIF3-f function in skeletal muscles: to stand at the crossroads of atrophy and hypertrophy. Cell Cycle 7 1698-1701. (doi:10.4161/cc.7.12.6090)

Deasy BM, Schugar RC \& Huard J 2008 Sex differences in muscle-derived stem cells and skeletal muscle. Critical Reviews in Eukaryotic Gene Expression 18 173-188. (doi:10.1615/CritRevEukarGeneExpr.v18.i2.60)

Evans WJ 2010 Skeletal muscle loss: cachexia, sarcopenia, and inactivity. American Journal of Clinical Nutrition 91 1123S-1127S. (doi:10.3945/ ajcn.2010.28608A)

Fielitz J, Kim MS, Shelton JM, Latif S, Spencer JA, Glass DJ, Richardson JA, Bassel-Duby R \& Olson EN 2007 Myosin accumulation and striated muscle myopathy result from the loss of muscle RING finger 1 and 3. Journal of Clinical Investigation 117 2486-2495. (doi:10.1172/JCI32827)

Gokhin DS, Ward SR, Bremner SN \& Lieber RL 2008 Quantitative analysis of neonatal skeletal muscle functional improvement in the mouse. Journal of Experimental Biology 211 837-843. (doi:10.1242/jeb.014340)

Hassink GC, Zhao B, Sompallae R, Altun M, Gastaldello S, Zinin NV, Masucci MG \& Lindsten K 2009 The ER-resident ubiquitin-specific protease 19 participates in the UPR and rescues ERAD substrates. EMBO Reports 10 755-761. (doi:10.1038/embor.2009.69)

Heldring N, Pike A, Andersson S, Matthews J, Cheng G, Hartman J, Tujague M, Strom A, Treuter E, Warner M et al. 2007 Estrogen receptors: how do they signal and what are their targets. Physiological Reviews $\mathbf{8 7}$ 905-931. (doi:10.1152/physrev.00026.2006)

Hershko A \& Ciechanover A 1992 The ubiquitin system for protein degradation. Annual Review of Biochemistry 61 761-807. (doi:10.1146/ annurev.bi.61.070192.003553)
Hewitt SC \& Korach KS 2002 Estrogen receptors: structure, mechanisms and function. Reviews in Endocrine \& Metabolic Disorders 3 193-200. (doi:10.1023/A:1020068224909)

Higashimura Y, Terai T, Yamaji R, Mitani T, Ogawa M, Harada N, Inui H \& Nakano Y 2011 Kelch-like 20 up-regulates the expression of hypoxiainducible factor- $2 \alpha$ through hypoxia- and von Hippel-Lindau tumor suppressor protein-independent regulatory mechanisms. Biochemical and Biophysical Research Communications 413 201-205. (doi:10.1016/ j.bbrc.2011.08.058)

Ihemelandu EC 1981 Comparison of effect of oestrogen on muscle development of male and female mice. Acta Anatomica 110 311-317. (doi:10.1159/000145442)

Kato S, Tora J, Yamauchi J, Masushige S, Bellard M \& Chambon P 1992 A far upstream estrogen response element of the ovalbumin gene contains several half-palindromic $5^{\prime}$-TGACC- $3^{\prime}$ motifs acting synergistically. Cell 68 731-742. (doi:10.1016/0092-8674(92)90148-6)

Kedar V, McDonough H, Arya R, Li HH, Rockman HA \& Patterson C 2004 Muscle-specific RING finger 1 is a bona fide ubiquitin ligase that degrades cardiac troponin I. PNAS 101 18135-18140. (doi:10.1073/ pnas.0404341102)

Kiens B 2006 Skeletal muscle lipid metabolism in exercise and insulin resistance. Physiological Reviews 86 205-243. (doi:10.1152/physrev. 00023.2004)

Lee JG, Kim W, Gygi S \& Ye Y 2014 Characterization of the deubiquitinating activity of USP19 and its role in endoplasmic reticulumassociated degradation. Journal of Biological Chemistry 289 3510-3517. (doi:10.1074/jbc.M113.538934)

Lephart ED, Setchell KD, Handa RJ \& Lund TD 2004 Behavioral effects of endocrine-disrupting substances: phytoestrogens. ILAR Journal $\mathbf{4 5}$ 443-454. (doi:10.1093/ilar.45.4.443)

Liu Q, Xu WG, Luo Y, Han FF, Yao XH, Yang TY, Zhang Y, Pi WF \& Guo XJ 2011 Cigarette smoke-induced skeletal muscle atrophy is associated with up-regulation of USP-19 via p38 and ERK MAPKs. Journal of Cellular Biochemistry 112 2307-2316. (doi:10.1002/jcb.23151)

Loots GG, Ovcharenko I, Pachter L, Dubchak I \& Rubin EM 2002 rVista for comparative sequence-based discovery of functional transcription factor binding sites. Genome Research 12 832-839. (doi:10.1101/gr. 225502. Article published online before print in April 2002)

Martini PG \& Katzenellenbogen BS 2001 Regulation of prothymosin a gene expression by estrogen in estrogen receptor-containing breast cancer cells via upstream half-palindromic estrogen response element motifs. Endocrinology 142 3493-3501. (doi:10.1210/endo.142.8.8314)

McCormick KM, Burns KL, Piccone CM, Gosselin LE \& Brazeau GA 2004 Effects of ovariectomy and estrogen on skeletal muscle function in growing rats. Journal of Muscle Research and Cell Motility 25 21-27. (doi:10.1023/B:JURE.0000021398.78327.39)

Mei Y, Hahn AA, Hu S \& Yang X 2011 The USP19 deubiquitinase regulates the stability of c-IAP1 and c-IAP2. Journal of Biological Chemistry 286 35380-35387. (doi:10.1074/jbc.M111.282020)

Moran AL, Nelson SA, Landisch RM, Warren GL \& Lowe DA 2007 Estradiol replacement reverses ovariectomy-induced muscle contractile and myosin dysfunction in mature female mice. Journal of Applied Physiology 102 1387-1393. (doi:10.1152/japplphysiol.01305.2006)

Nishimura M, Nikawa T, Kawano Y, Nakayama M \& Ikeda M 2008 Effects of dimethyl sulfoxide and dexamethasone on mRNA expression of housekeeping genes incultures of $\mathrm{C} 2 \mathrm{C} 12$ myotubes. Biochemical and Biophysical Research Communications 367 603-608. (doi:10.1016/j.bbrc. 2008.01.006)

Ogawa M, Yamaji R, Higashimura Y, Harada N, Ashida H, Nakano Y \& Inui H 2011 17ß-estradiol represses myogenic differentiation by increasing ubiquitin-specific peptidase 19 through estrogen receptor $\alpha$. Journal of Biological Chemistry 286 41455-41465. (doi:10.1074/jbc. M111.276824)

Ogawa M, Kariya Y, Kitakaze T, Yamaji R, Harada N, Sakamoto T, Hosotani K, Nakano Y \& Inui H 2013 The preventive effect of $\beta$-carotene

Published by Bioscientifica Ltd 
on denervation-induced soleus muscle atrophy in mice. British Journal of Nutrition 109 1349-1358. (doi:10.1017/S0007114512003297)

Ontell M, Feng KC, Klueber K, Dunn RF \& Taylor F 1984 Myosatellite cells, growth, and regeneration in murine dystrophic muscle: a quantitative study. Anatomical Record 208 159-174. (doi:10.1002/ar. 1092080203)

Petz LN \& Nardulli AM 2000 Sp1 binding sites and an estrogen response element half-site are involved in regulation of the human progesterone receptor A promoter. Molecular Endocrinology 14 972-985. (doi:10.1210/ mend.14.7.0493)

Peth A, Besche HC \& Goldberg AL 2009 Ubiquitinated proteins activate the proteasome by binding to Usp14/Ubp6, which causes 20 S gate opening. Molecular Cell 36 794-804. (doi:10.1016/j.molcel.2009.11.015)

Polge C, Heng AE, Jarzaguet M, Ventadour S, Claustre A, Combaret L, Béchet D, Matondo M, Uttenweiler-Joseph S, Monsarrat B et al. 2011 Muscle actin is polyubiquitinylated in vitro and in vivo and targeted for breakdown by the $\mathrm{E}_{3}$ ligase MuRF1. FASEB Journal 25 3790-3802. (doi:10.1096/fj.11-180968)

Prossnitz ER, Arterburn JB, Smith HO, Oprea TI, Sklar LA \& Hathaway HJ 2008 Estrogen signaling through the transmembrane $G$ proteincoupled receptor GPR30. Annual Review of Physiology 70 165-190. (doi:10.1146/annurev.physiol.70.113006.100518)

Srikanthan P, Hevener AL \& Karlamangla AS 2010 Sarcopenia exacerbates obesity-associated insulin resistance and dysglycemia: findings from the National Health and Nutrition Examination Survey III. PLOS ONE 5 e10805. (doi:10.1371/journal.pone.0010805)
Sundaram P, Pang Z, Miao M, Yu L \& Wing SS 2009 USP19-deubiquitinating enzyme regulates levels of major myofibrillar proteins in L6 muscle cells. American Journal of Physiology. Endocrinology and Metabolism 297 E1283-E1290. (doi:10.1152/ajpendo.00409.2009)

Tiao G, Hobler S, Wang JJ, Meyer TA, Luchette FA, Fischer JE \& Hasselgren PO 1997 Sepsis is associated with increased mRNAs of the ubiquitin-proteasome proteolytic pathway in human skeletal muscle. Journal of Clinical Investigation 99 163-168. (doi:10.1172/JCI119143)

Tintignac LA, Lagirand J, Batonnet S, Sirri V, Leibovitch MP \& Leibovitch SA 2005 Degradation of MyoD mediated by the SCF (MAFbx) ubiquitin ligase. Journal of Biological Chemistry 280 2847-2856. (doi:10.1074/jbc.M411346200)

Wang F, Porter W, Xing W, Archer TK \& Safe S 1997 Identification of a functional imperfect estrogen-responsive element in the $5^{\prime}$-promoter region of the human cathepsin D gene. Biochemistry 36 7793-7801. (doi:10.1021/bi963100j)

Welle S, Tawil R \& Thornton CA 2008 Sex-related differences in gene expression in human skeletal muscle. PLOS ONE 3 e1385. (doi:10.1371/ journal.pone.0001385)

White RB, Biérinx AS, Gnocchi VF \& Zammit PS 2010 Dynamics of muscle fibre growth during postnatal mouse development. BMC Developmental Biology 10 21. (doi:10.1186/1471-213X-10-21)

Wiik A, Ekman M, Johansson O, Jansson E \& Esbjörnsson M 2009 Expression of both oestrogen receptor $\alpha$ and $\beta$ in human skeletal muscle tissue. Histochemistry and Cell Biology 131 181-189. (doi:10.1007/ s00418-008-0512-x)

Received in final form 16 April 2015

Accepted 21 April 2015

Accepted Preprint published online 21 April 2015
(C) 2015 Society for Endocrinology Printed in Great Britain 